\title{
The lessons of biogeochemistry
}

\author{
Alan R. Townsend
}

Published online: 30 March 2017

(C) Springer International Publishing Switzerland 2017

Our lives are not our own. We are bound to others, past and present, and by each crime and every kindness, we birth our future. -David Mitchell, Cloud Atlas

Years ago I sat upon a wooden bench in an extraordinary backyard on the windward coast of Hawaii's Big Island. A patio was beneath my feet, an intricate and perfectly repeating array of ochre sandstone and water-pockmarked lava with accents of obsidian and cowry shells. The patio swept gently towards a path of the same construction, one that wound amidst a grove of manicured trees, each one different, a pastiche of varied form and color that became a single astonishing whole. To my right a small pond of lilies and koi above a bed of the same lava, like the patio it too giving way to a narrower winding course of identical foundation. Stream crossed path by way of an arched and bright red bridge, before the former split into terminal braids and disappeared back into the land.

It was all the work of the ancient man who sat beside me. Johnny was Japanese, but had lived in or near this tiny Hawaiian town for 83 of his 94 years. I came to him in hopes of learning the history of a pasture nearby in which I was studying soil carbon turnover. I left having learned that and so much more.

A. R. Townsend $(\varangle)$

University of Colorado, Boulder, CO, USA

e-mail: alan.townsend@colorado.edu
He spoke of each tree in the yard, where it came from, why it was there. Of the rise and fall of sugar cane on the Hamakua coast. Of being Japanese American in the second world war. Of the devastating tsunami that struck a schoolhouse just down the hill from where we sat months after that war ended, drowning four teachers and twenty students. Of a community sometimes divided, sometimes unbreakably connected. Of his devotion to the latter.

Biogeochemistry is a science of connections in time and space. The elements which grace the pages of this journal are linked to their birth in celestial ovens at the very dawn of time. Once they found their way into living beings, that life persisted by sharing those elements not only with each other, but with the air and rocks and water on which it all depends. Today, a tree in the middle of the Amazon perhaps owes its existence to the wandering habits of giant beasts that walked the land thousands of years before. To the nutrient-laden dust that links teeming rainforest to treeless African deserts. To the community it helps build in its canopy and roots, and to ones it has never met and will never see. It is both a moment in time and a mirror of historical oscillations long preceding its existence, and destined to continue long after it is gone. 
Biogeochemistry also teaches us those oscillations are not all the same. Cycles persist, pendulum swings are inevitable, but there are moments in history where a given swing catapults everyone into playing a new game, if not for good, then at least for a very long time. Oxygen rises. Something crawls out of the sea never to return. Plants evolve. A meteor strikes. And humans arrive.

Many of us feel we are now staring at the knife edge of another such swing. And that recent events in this country are only hitting the accelerator in the wrong direction. What should we do? What can we do? The past two issues of this journal included editorials urging our community to speak out, to push back, to defend our science and to engage with those it serves. And to couple all of it with continued good science, some of which will appear here.

I take no issue with any of this. It's heartening to see our community speak up and reach out, and to see the kind of optimism that still pervades so many, as evidenced in the inaugural editorial. But as I consider the science of biogeochemistry at this moment in history, I find myself more drawn to its broader lessons than to a burning need to publish or read the next journal article. That may raise some eyebrows, so let me explain.

Good science is the foundation upon which our discipline rests, and we should continue to push it forward. From the joy of new discovery to the applications of our work to real world problems, it matters. A lot. I'll continue to read the science published here and elsewhere, to enjoy it, to be certain of its importance. But like the cycles we study, there are moments where our relative efforts should shift. That notion is inherent in the call to speak out and defend the science, but for our science to continue to grow, and to matter, those efforts need to go even further.

First, we should heed biogeochemistry's lessons of connections and community. That Amazonian tree does not suddenly develop its own community or connections overnight, it builds them over decades of sustained effort, and from a platform provided by those that preceded it. As trust in not only our science but the enterprise as a whole erodes, we all need to invest in the long, slow, consistent work from which communities are built and trust is gained. Many of us do that already in varying ways as part of our individual lives, but making it a stated priority through the lens of our chosen scientific disciplines, and then supporting and rewarding those efforts, is essential.

I say reward because while the personal satisfaction of sustained engagement with those who do not think as we do can be enormous, the work does not translate easily into the metrics of career advancement. That must change, or those careers themselves will begin to disappear. When a colleague, especially a rising junior scientist, decides to put in the necessary long hours around engagement and building trust instead of publishing another paper, we should celebrate and tangibly reward that effort, that accomplishment, that bravery. And we should recognize that akin to the very processes we study, the true outcomes of this effort may not be apparent for years or even generations. But that without those efforts, the cycle's oscillations will trend in a very different direction.

Second, we should remember the lessons of resilience and function and just pure wonder in the ecosystems we study. We can (as we still do) debate how much varying aspects of diversity matter to ecosystem processes. We should not debate the importance of diversity and inclusion to our own human enterprises. It matters from any metric you want to choose: morals, ethics, creativity, productivity, and translation into societal good. We've made strides in our own science, but not enough. Until our labs and classrooms and meetings and field campaigns truly represent the faces and backgrounds of the world we study and seek to help, until everyone doing our science can pursue it without fear of bias or rejection or harassment based on who they are and how they look, we are falling short. Current events in this country only highlight a chronic need to do better. Once again, our discipline itself depends on it.

Finally, to use an old cliché, we should remember that history repeats itself in ways both abhorrent and welcomed. The fears now gripping our community and much of the United States may well give way to a spring renewal of our own, to a swing away from hate and fear and division and denial, to a time when we can pursue our science again with greater support, inclusion and effect. An eternal optimist, I suspect they will. In that Hawaiian backyard, Johnny spoke with both emotion and satisfaction of the aftermath of both war and tsunami, of a community pulling together after searing moments of distrust, hate and grief. He noted with wonder the very existence of the yard 
before him and the fact that he was still here and able to tend it. I have long believed that the true nature of a community is revealed not in its normal days, but in the response to its worst ones.

Yet there is little question we live in a time where a darker path for both this nation and this world is a distinct possibility. So yes, the science we do matters, and it provides a unique and critical entry point for us to engage in larger conversations. But the path our country and world follows will not rest upon the next article any one of us publishes. It will rest upon the community we all choose to build.

Alan R. Townsend is a Professor of Environmental Studies, Fellow of the Institute of Arctic and Alpine Research and Associate Vice Chancellor for Research at the University of Colorado. 